\title{
Effect Of Speeds and Under Inlet Pulsating Flow Conditions onthe Performance ofthe Twin-Entry Mixed Flow Turbine
}

\author{
HAMID AMRANI ${ }^{12}$, MOHAMED BENCHERIF ${ }^{12}$, MOHAMMED MENAOUER BENCHERIF ${ }^{23}$, \\ MOHAMED KAMEL HAMIDOU ${ }^{12}$ \\ Mechanical Engineering Department, USTO-MB, BP 1505, El M'Naouer 31000 - Oran, ALGERIA \\ LMA LABORATORY, USTO-MB, BP 1505, El M'Naouer 31000 - Oran, ALGERIA \\ Mechanical Engineering Department, ENPO-MA, BP 1523, El M'Naouer 31000 - Oran, ALGERIA
}

\begin{abstract}
This study has highlighted how the needs of drastically reduces carbon, pollutant emissions and energy recovery in vehicle propulsion systems. The object of this research is to reduce emissions of gas pollutants by investigating the impact of speed and frequency towards the automotive turbocharger. This will definitely lead to a reduction in fuel consumption leading to a reduction in the amount of $\mathrm{CO} 2$ gas emissions. The present work is conducted with the view to push one step closer towards the full incorporation of the pulsating flow efficiency in the turbine design. In addition, the pulse frequency and the pulsating flow frequency effects the performances of the turbine are analyzed. The numerical results of the present study are compared with the experimental data. ANSYS-CFX software is used to solve the equations of a viscous, compressible, highly unsteady and three dimensional turbine inflows. The simulations are conducted at 29,500 rpm, 41,500 rpm and 59,740 rpm and respectively at 50\%,70\% and 100\% design speed for both $40 \mathrm{~Hz}, 56,8 \mathrm{~Hz}$ and $80 \mathrm{~Hz}$ pulsating flow inlet conditions.
\end{abstract}

Key-Words: Propulsion; rotation speed; Twin-Entry Mixed Flow Turbine; CFD; Turbulence.

Received: May 14, 2020. Revised: October 31, 2020. Accepted: November 18, 2020. Published: November 30, 2020.

\section{Introduction}

The importance and availability of road vehicles which operate over wide range of speeds and under inlet pulsating flow conditions are fastly growing. The gas pollutants of this vehicle must be reduced; this could be achieved by investigating the influence of speed and frequency towards the automotive turbocharger, since if the $\mathrm{CO} 2$ content of the combustion products rises above $15 \%$ it would be harmful to the health. It should be emphasized that turbocharged internal combustion engines work for less toxic gas emissions with a higher air / fuel ratio (3-5\% excess air) and result in a significant increase in the specific power output, both features are attractive achievements.

US Environmental Protection Agency conducted a study of $\mathrm{CO} 2$ emissions of different end-use sectors in the United States in 2008 [1] showed approximately $32 \%$ of $\mathrm{CO} 2$ emissions are from the transportation sector, and almost entirely from fossil fuel combustion. Tolga and al [2] develop the Matching of Double Entry Turbines for the Next Generation of Highly Boosted Gasoline Engines Carla and al [3] focuses on exploiting ways to decrease consumption of fuel and reduce emissions from gasoline road vehicles, with turbocharging mechanisms, and the combination of lowcomplexity mechanisms (fuel cut, stop-start and downsizing with turbocharging), $\mathrm{CO} 2$ emissions and fuel consumption can be reduced by $15-49 \%$.The influences of the engine exhaust system as well as turbocharging have been investigated extensively. Bencherif and al [4] et [5] analyzed the performance of a twin-entry turbine under pulsed flow conditions. The results of this study show that the twin-entry turbine exhibits greater filling and emptying characteristic.

Klimstra J. [6] studied the performance of lean-burn stationary engines fueled by natural gas. It was found that limitations for the NOx emissions restrict the developments in cylinder load and shaft 
efficiency. The range of prominent variable geometry technologies that are commercially available, for both turbines and compressors was detailed by Adam and al [7]. Ugur [8] investigated the influence of the turbocharging system on the performance of the gas engine family, which is used in combined power plants. The results show that the turbocharger efficiency has a great impact on the engine efficiency. An increase of $1 \%$ in the turbocharger efficiency brings an increase of around $0.08 \%$ in the engine efficiency.

The twin entry turbine is an important component in the centrifugal machines. Optimizing the performance of a twin entry volute leads to improve the total performance of the machine. For this purpose, it is of high interest to compare the effect and benefits of the pulse frequency as well as the speed rotation, maximum kinetic energy and appropriated incidence angle to the rotor and minimum losses. The twin-entry mixed inflow turbine is studied under highly pulsating unfavorable flow. It is fortunate that the turbine is able to accept these conditions without a complete deterioration of its performance.

Several experimental investigations on the single entry mixed inflow turbine performance was performed. Three mixed flow turbines, with rotor A, $\mathrm{B}$ and $\mathrm{C}$, have been designed to meet the above mentioned constrains and then tested at Imperial College by Abidat [9] and Abidat and al. [10], the two rotors $\mathrm{A}$ and $\mathrm{C}$ have a 20 degrees constant rotor inlet blade angle and differ only by the number of blades: Turbine $\mathrm{C}$ has only 10 blades while rotor $\mathrm{A}$ has 12 blades. Vincenzo and al [11] presented an experimental campaign developed on a turbocharger waste-gated turbine for gasoline engine application. The effect of pulse amplitude and frequency on the mixed flow turbine was investigated by Chen and al. [12]. The performance of mixed flow turbine with different rotors has been investigated by Arcoumanis et al. [13]. Hakeem and al. [14] presented a steady and unsteady performances of two mixed flow turbocharger turbine rotors, a detailed assessment of the effect of volute geometry on the turbine performance has been carried out, which confirmed that the geometry of volute plays a very important role in the overall performance of a turbine. A method to predict the performance of a mixed flow turbine under both steady and unsteady conditions was proposed by Abidat and al. [15]. Hamel and al. [16] analyzed the effect of the volute inlet flow conditions on its performance (efficiency, exit flow angle, etc.). Hamel and al. [17] conducted a steady and unsteady flow performance analyses and a numerical performance prediction of a mixed flow turbine under inlet pulsating flow conditions. Sakai and al. [18] proposed a novel turbine concept specifically designed for exhausts pulse flow energy conservation and EGR control. In order to combine both these features, an asymmetrically divided double-entry turbine was developed to respond to the imbalance of mass flow due to EGR extraction from one side. Mahfoudh and al. [19] performed a study of the unsteady performances related to the pulsating flows of a twin-entry radial turbine in engine-like conditions and the hysteresis-like behaviour during the pulses period.

The numerical simulations were performed using ANSYS-CFX code. The steady and unsteady flow both are characterized by a pressure ratio range between 1.1 and 2.4 at 29,500 rpm, 41,500 rpm and $59,740 \mathrm{rpm}(50 \%, 70 \%$ and $100 \%$ design speed respectively) for both $40 \mathrm{~Hz}, 56,8 \mathrm{~Hz}$ and $80 \mathrm{~Hz}$ pulsating flow inlet conditions and inlet total temperature of $342.2^{\circ} \mathrm{K}$.the numerical results of the turbine efficiency are compared with the experimental data reasonable agreement is obtained with a maximum discrepancy of $3.75 \%$, The influence of rotation speed and the pulsating flow on distribution of the pressure in the rotor are presented, the swallowing capacity under unsteady regime is obtained for the twin-entry volute, characterized by the Dale's loop at $50 \%, 70 \%$ and $100 \%$ equivalent speed and $180^{\circ}$ out of phase admission, for $56,8 \mathrm{~Hz}, 80 \mathrm{~Hz}$ and the characteristic pulsating flow conditions Are studied and the instantaneous mass flow rate at different frequencies and stations of the twin entry mixed flow turbine stage.

\section{Methods and Materials}

\subsection{Mixed Inflow Geometry}

The turbine wheel under investigations is a mixed inflow type. The blade angle is constant (named rotor A at the laboratory of Imperial College), a volute cross section area is shown in Fig. 1. The main geometrical parameters are given in Table 1 . The twin-entry turbine geometries are presented in Fig. 1. The volutes of the twin -entry turbine are designed by Bencherif and al [4]. 
Table 1.Turbine geometry

\begin{tabular}{|l|l|}
\hline Volute inlet area & $2.12 \times 10^{-3} \mathrm{~m} 2$ \\
\hline Volute inlet radius & $82.50 \times 10^{-3} \mathrm{~m}$ \\
\hline Rotor inlet mean diameter & $83.58 \times 10^{-3} \mathrm{~m}$ \\
\hline Rotor inlet blade height & $17.99 \times 10^{-3} \mathrm{~m}$ \\
\hline Rotor inlet blade angle & $20.0 \circ$ degree \\
\hline Rotor inlet cone angle & 40.0 degree \\
\hline Exducer hub diameter & $27.07 \times 10^{-3} \mathrm{~m}$ \\
\hline Exducer shroud diameter & $78.65 \times 10^{-3} \mathrm{~m}$ \\
\hline Rotor exit mean blade angle & -52.0 degree \\
\hline Rotor axial length & $40.00 \times 10^{-3} \mathrm{~m}$ \\
\hline Number of blades & 12 \\
\hline Radial and axial tip clearance & $0.40 \times 10^{-3} \mathrm{~m}$ \\
\hline
\end{tabular}

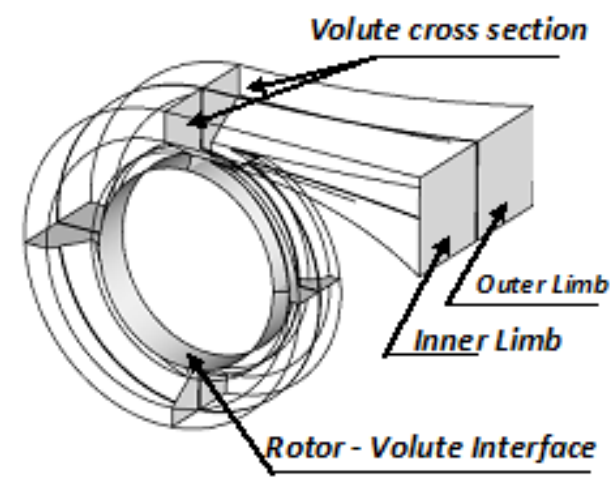

Fig.1 Volute of the mixed flow turbine casing.

\subsection{Turbulent Flow Model}

The highly three-dimensional flow in the mixed flow turbine is obtained by solving numerically the compressible Reynolds Averaged Navies Stokse (RANS) equations. The turbulence is modeled by the standard $\mathrm{k}-\varepsilon$ model. This model is based on the eddy viscosity concept which assumes that the Reynolds stresses can be expressed in terms of the mean velocity gradients and the eddy or turbulent viscosity in a manner analogous to the viscous stresses for laminar Newtonian flows.

\subsubsection{Continuity Equation} $\frac{\partial \rho}{\partial t}+\nabla \cdot(\rho \vec{U})=0$

(1)Where $\rho$ and $\vec{U}$ are the density and the mean velocity vector respectively.

\subsubsection{Momentum Equations}

$\frac{\partial(\rho \vec{U})}{\partial t}+\nabla \cdot(\rho \vec{U} \otimes \vec{U})=-\nabla P \cdot\left[\mu_{e f f}(\nabla \vec{U}+\right.$ $\left.\left.(\nabla \vec{U})^{\gamma}\right)\right]+S_{M}$
Where $\mathrm{S}_{\mathrm{M}}$ Isthe sum of the body forces, and $\mu_{\text {eff }}$ is the Effective Viscosity defined by:

$\mu_{\text {eff }}=\mu+\mu_{t}$

Where

$\mu_{t}=\rho C_{\mu} \frac{k^{2}}{\varepsilon}$

And $P^{\prime}$ is modified pressure, defined by:

$P^{\prime}=P+\frac{2}{3} \rho k+\frac{2}{3} \mu_{e f f} \frac{\partial U_{k}}{\partial x_{k}}(5)$

Where $\vec{u}, P, \delta, \tau,-\rho \overline{u_{\imath} u_{\jmath}}$, and $S_{M}$ are the fluctuating velocity vector, the pressure, the Kronecker delta symbol, the molecular stress tensor, the Reynolds stress tensor and a source term respectively. The Coriolis and centrifugal forces are included in the source term.

\subsubsection{Energy Equation}

$\frac{\partial \rho H}{t}+\nabla \bullet(\rho \vec{U} H-\rho \overrightarrow{\vec{u} h}-\lambda \nabla T)=\frac{\partial P}{t}$

In this equation, $\mathrm{H}$ is the mean total enthalpy given by:

$H=h_{s}+\frac{1}{2} \vec{U}^{2}+k$

Where $h_{s}$ is the mean static enthalpy, $\lambda$ is the thermal conductivity, $\mathrm{T}$ is the mean static temperature and the additional term $\mathrm{k}$ in the total energy equation is the turbulent kinetic energy defined as follows:

$k=\frac{1}{2} \vec{U}^{2}$

Static temperature, static pressure $P$ and density $\rho$ are related by the equation of state:

$P=\rho R T$, where $\mathrm{R}$ is the air gas constant.

We define the reduced mass flow rate:

$\dot{m}_{r}=10^{5} \dot{m} \sqrt{T_{0 *} / P_{0 *}}$

The expansion ratio:

$P_{r}=P_{0 *} / P_{4}$

(10)And the total to static efficiency:

$\eta_{t s}=\left(h_{0 *}-h_{4}\right) / c p T_{0 *}\left[1-\left(\frac{P_{4}}{P_{0}}\right)\right]^{(\gamma-1) / \gamma}$

The $\mathrm{k}-\varepsilon$ model assumes that the eddy viscosity $\mu_{t}$ is linked to the turbulent kinetic energy $\mathrm{k}$ and its dissipation rate $\varepsilon$ through the following relation:

$\mu_{t}=\rho C_{\mu} \frac{k^{2}}{\varepsilon}$

where $C_{\mu}=0.09$ and $\mathrm{k}, \varepsilon$ are defined through the following two equations:

$$
\frac{\partial(\rho K)}{\partial t}+\nabla(\rho U K)=\nabla\left[\left(\mu+\frac{\mu_{t}}{\sigma_{k}}\right) \nabla K\right]+P_{k}-\rho \varepsilon
$$


$\frac{\partial(\rho \varepsilon)}{\partial t}+\nabla(\rho U \varepsilon)=\nabla\left[\left(\mu+\frac{\mu_{t}}{\sigma_{\varepsilon}}\right) \nabla \varepsilon\right]+\frac{\varepsilon}{K}\left(C_{\varepsilon 1} P_{K}-\right.$

$\left.C_{\varepsilon 2} \rho \varepsilon\right)$

In this model, $P_{k}$ is the turbulence production and the flowing constants are determined experimentally from a wide range of turbulent flows (Patankar and Spalding[20]) $\quad \sigma_{k}=1.00, \quad \sigma_{\varepsilon}=1.30 C_{\varepsilon 1}=$ $1.44 C_{\varepsilon 2}=1.920$.

\section{Computational Analysis}

The ANSYS-CFX software uses a single cell, collocated grid to overcome the decoupling of velocity and pressure [21]. The method is similar to that used by Rhie and Chow [22], with a number of extensions to achieve numerical solutions that are independent of both the under relaxation factor and the time step size of the steady-state solution. The method improves the robustness of the discretization when the pressure varies rapidly or is affected by body forces. The pressure-velocity coupling is achieved using a coupled solver, which solves the hydrodynamic equations (for $\mathrm{u}, \mathrm{v}, \mathrm{w}$, and $\mathrm{p}$ ) as a single system. This solution approach uses a fully implicit of the equations at any given time step. At the domain inlet, the flow is assumed subsonic, and therefore the total pressure, the total temperature and a medium intensity of turbulence $(5 \%)$ in the stationary frame of reference as well as the flow direction are imposed. For the analysis presented here, a $\mathrm{k}-\varepsilon$ turbulence model with scalable wall functions was used. The $\mathrm{k}-\varepsilon$ turbulence model is an eddy-viscosity, two-equation turbulence model. It is very widely used as a general purpose model and offers a good compromise between computational time and accuracy. Wall functions are used to relate the flow at the near wall node to the shear stress at the wall.

\subsection{Computational Geometry and Grids}

Computational grid of the mixed flow turbine, shown in Fig. 2, The ICEM CFD tool is used to build the turbine geometry and to generate the unstructured mesh. The flow domain is discredited into finite volumes method of tetrahedral elements and prism elements in the near wall layer. The Mesh Information of the twin mixed flow turbine is given in Table 2.

During the mesh generation process, care has to be taken when choosing the first grid spacing near wall boundaries to obtain a proper resolution of the boundary layer. As a result of the use of the wall function approach to model the flow near the wall in the RNG $\mathrm{k}-\varepsilon$ turbulence model, and the $\mathrm{y}+$ value is controlled between 20 and 100 in order to properly capture the high gradients inside the boundary layer by using the wall function.

Table 2. Mesh characteristics of the turbocharger domain

\begin{tabular}{|c|c|c|}
\hline Domain & Nodes & Elements \\
\hline Rotor Part & 145173 & 548684 \\
\hline Volute Part & 317564 & 790872 \\
\hline All Domains & 462737 & 1339556 \\
\hline
\end{tabular}

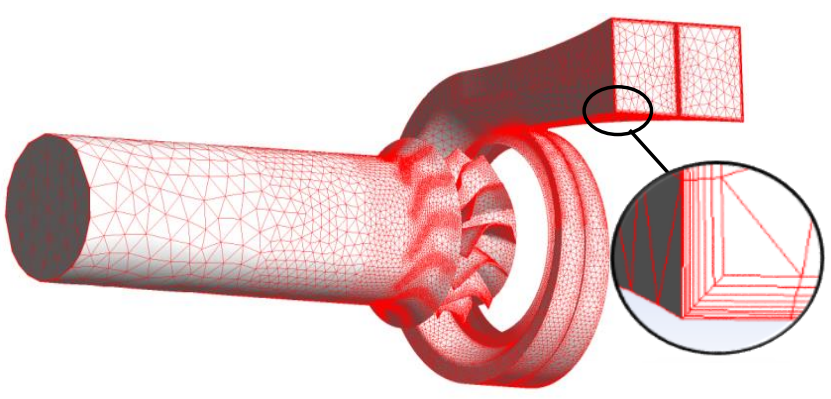

Fig.2.Exploded view of the Surface mesh.

\section{Results and Discussion}

In order to verify the reliability of any computational prediction it is necessary to compare the predicted results as much as possible with experimental findings. For the current analysis, the overall performance data from the turbine, as measured on the turbocharger test rig, were compared with that predicted by the CFD code.

In the Fig. 3, the equal admission swallowing capacity data for the twin-entry turbine, steady simulation were performed at constant speed with a varying pressure ratio for a range between 1.9 and 3, 3 at $100 \%$ of relative speed, which corresponded to a shaft speed of 59,740 rpm at full admission conditions. The demonstrates of the turbine efficiency characteristics by plotting total-to-static relative efficiency against pressure ratio, reasonable agreement is obtained with a maximum discrepancy of $3.75 \%$ compared to the experimental results, thanks to the uniformity of the flow which in lateral entry improve the distribution of the fluid at the volute outlet [4]. 


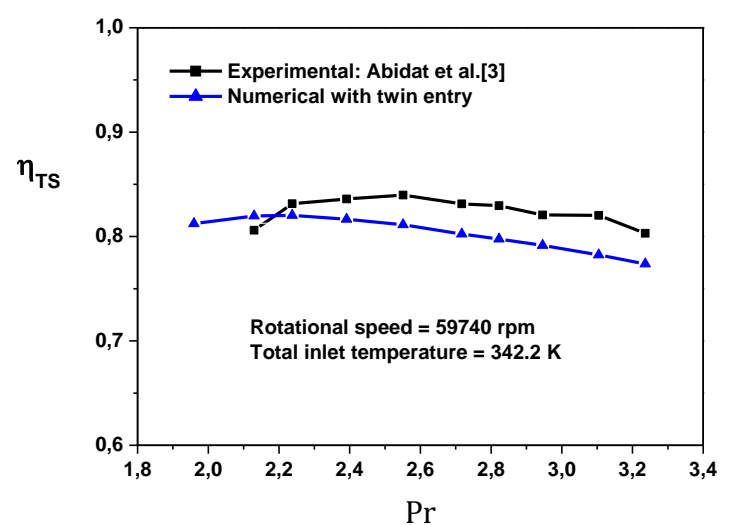

Fig.3. Equal admission efficiency predicted by the CFD in comparison with the experimental efficiency.

The Fig. 4 shows the distribution of the pressure in the rotor for frequency of $56.8 \mathrm{HZ}$ at different $50 \%$, $70 \%$ and $100 \%$ of equivalent speed, it should be noted that for all pressure ratios there is always a vacuum zone at the suction side. We observed that distribution of the pressure value equal to $1.5 \mathrm{bar}$ towards a pressure lower than atmospheric pressure equal to 0.9 bar for a maximum speed of $100 \%$, and for an equivalent speed of $50 \%$ and $70 \%$ Pressure is equal to 1.25 bar to a pressure equal to 1 bar. This expansion is due to the convergent cross-blade shape which causes a transformation of the potential energy from pressure to kinetic energy. Fig. 5 depicts the distribution of pressure for $50 \%$ speed, at $40 \mathrm{~Hz}, 56.8 \mathrm{~Hz}$ and $80 \mathrm{~Hz}$ frequency the distribution of the flow in an axisymmetric way at the entry of rotor by transforming the potential energy of gases into kinetic energy conformed to the free the twin entry volute design. And the distribution of the pressure is uniform despite the variation of the pulse frequency from $60 \mathrm{~Hz}$ to $80 \mathrm{~Hz}$, Where a high pressure value is observed for a frequency of $56.8 \mathrm{~Hz}$.
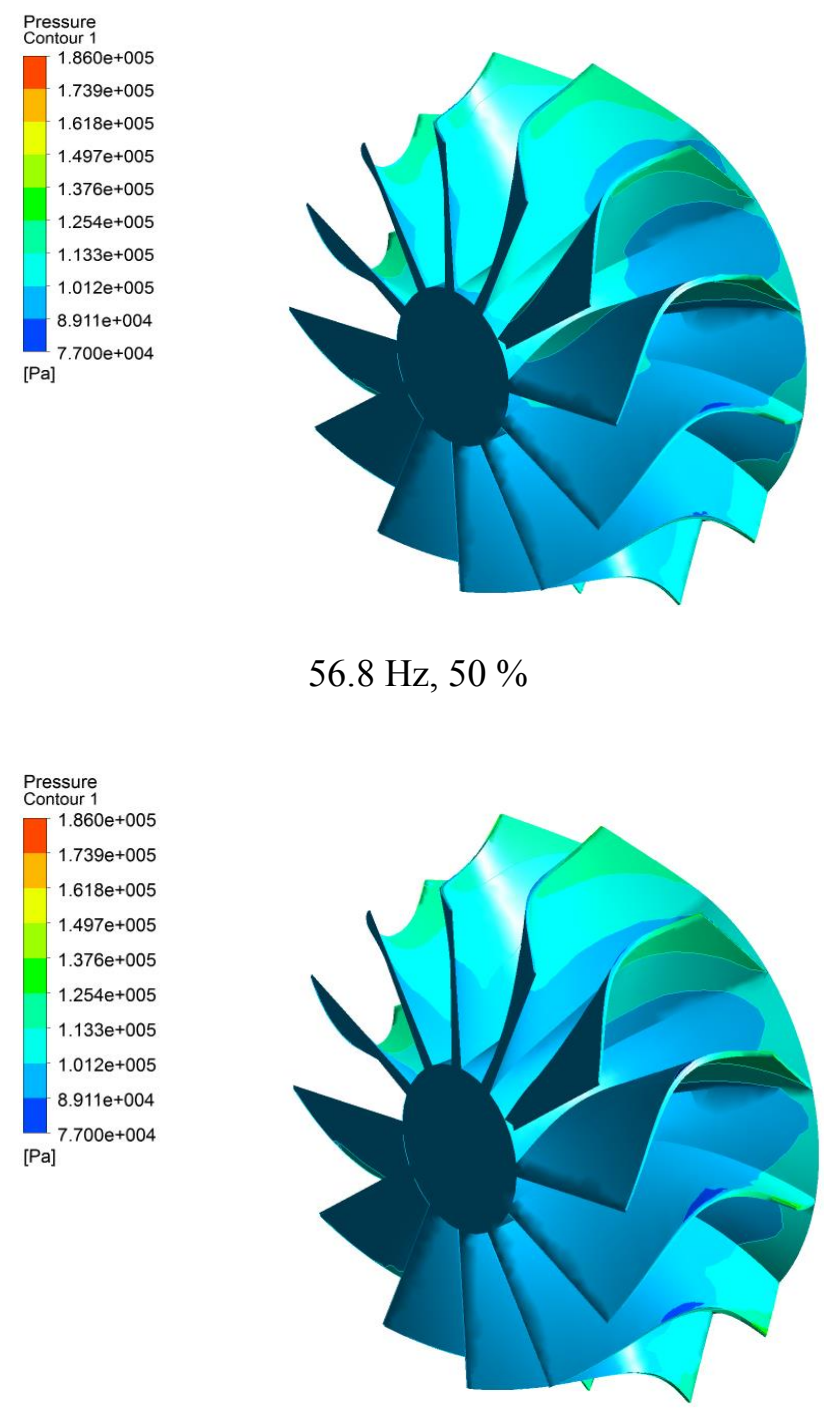

$56.8 \mathrm{~Hz}, 70 \%$
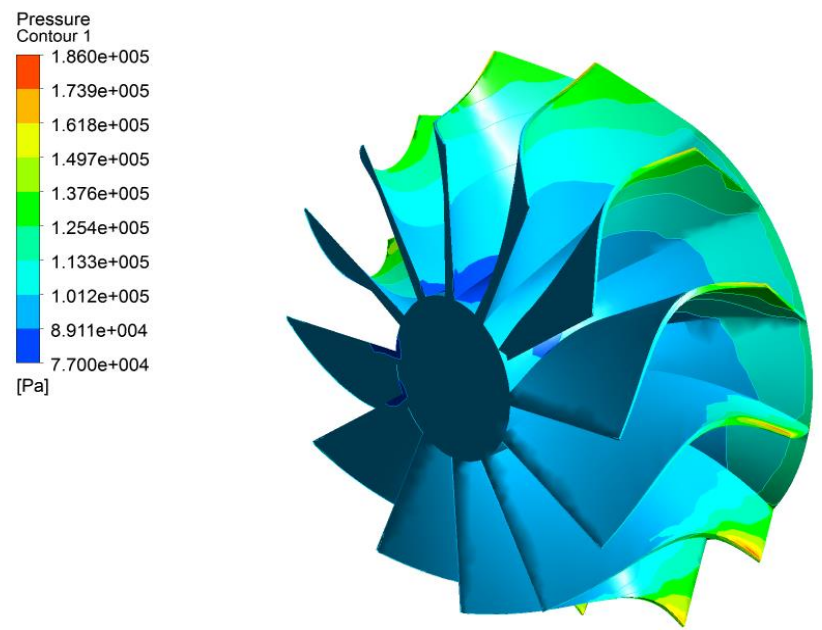

$56.8 \mathrm{~Hz}, 100 \%$

Fig.4. Plots for $56.8 \mathrm{~Hz}$ frequency of pressure in the rotor at $50 \%, 70 \%$ and $100 \%$ speed. 

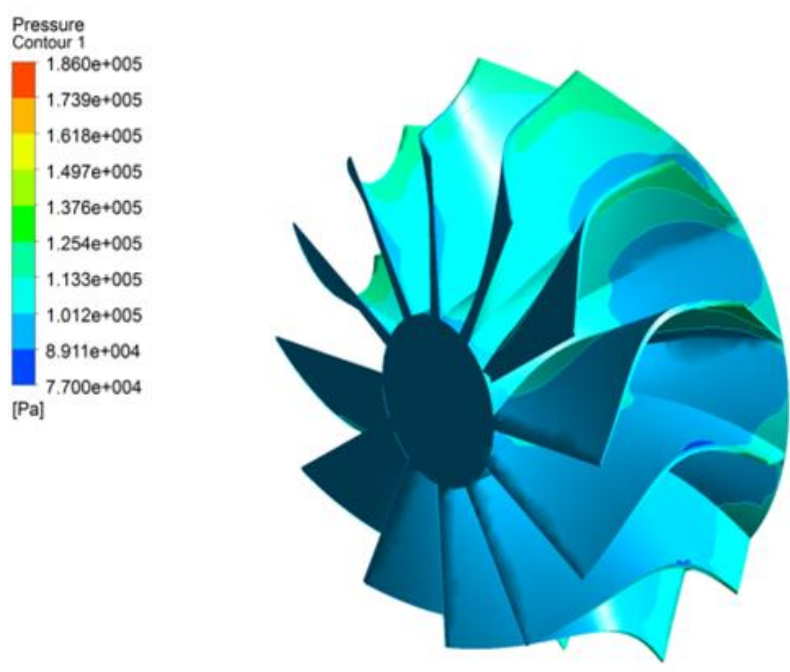

$40 \mathrm{~Hz}, 50 \%$
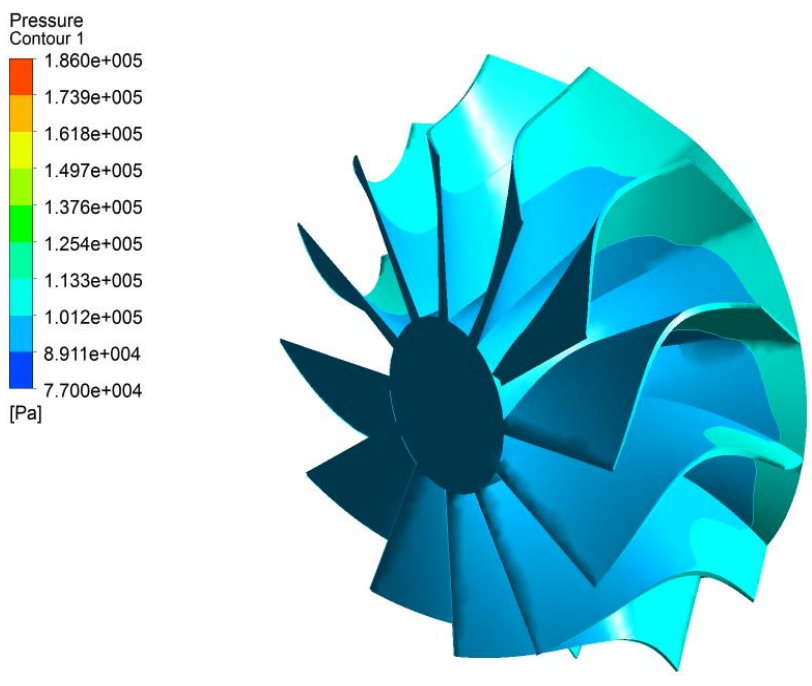

$56.8 \mathrm{~Hz}, 50 \%$
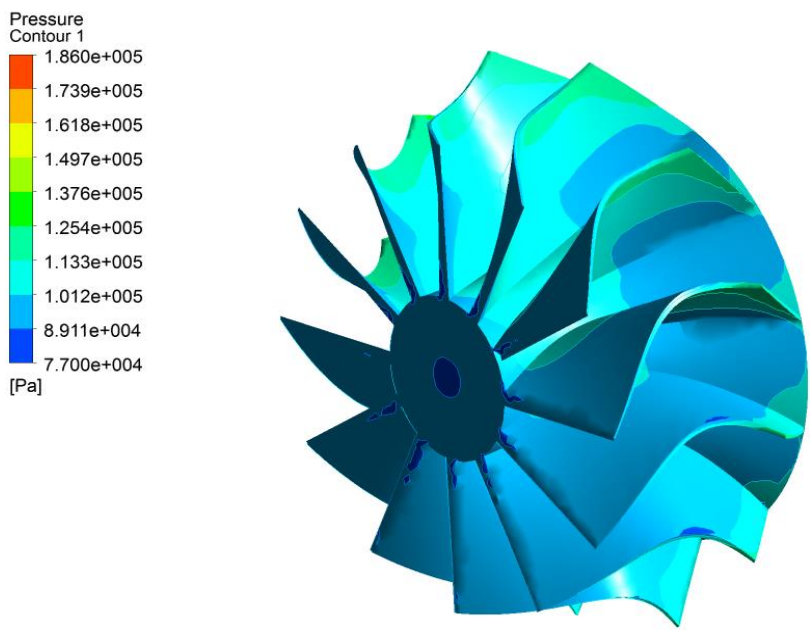

$80 \mathrm{~Hz}, 50 \%$

Fig.5. Plots for $50 \%$ speed of: pressure in the rotor at $40 \mathrm{~Hz}, 56.8 \mathrm{~Hz}$ and $80 \mathrm{~Hz}$ frequency.
The Fig. 6 and 7 shows the swallowing capacity of single entry and twin-entry turbine at $50 \%, 70 \%$ and $100 \%$ equivalent speed and $180^{\circ}$ out of phase admission, for $40 \mathrm{~Hz}, 56,8 \mathrm{~Hz}$ and 80 pulsating flow conditions are shown, where the unsteady performance characteristics are superimposed on the quasi-steady state constant speed curve. The turbine's performance is characterized as a hysteresis loop which encapsulates the equivalent quasi-steady state values. The deviation from the quasi-stationary approach increases with increasing pulse frequency. When the mass flow rate at the inlet decreases, the pressure ratio becomes higher. The characteristic loop observed experimentally by Dale and Watson [22] is clearly reproduced by the present simulation for different pulse frequencies. The deviation from the quasi-stationary approach increases with increasing pulse frequency. In unequal flow conditions, calculating the total swallowing capacity of the twin-entry turbine is not straightforward. The pressure ratios of the two entries will decrease the range covered during a cycle, as well as the double looping in the overall swallowing capacity representing both entries, which means the twin-entry turbine exhibits more of a filling and emptying characteristic.

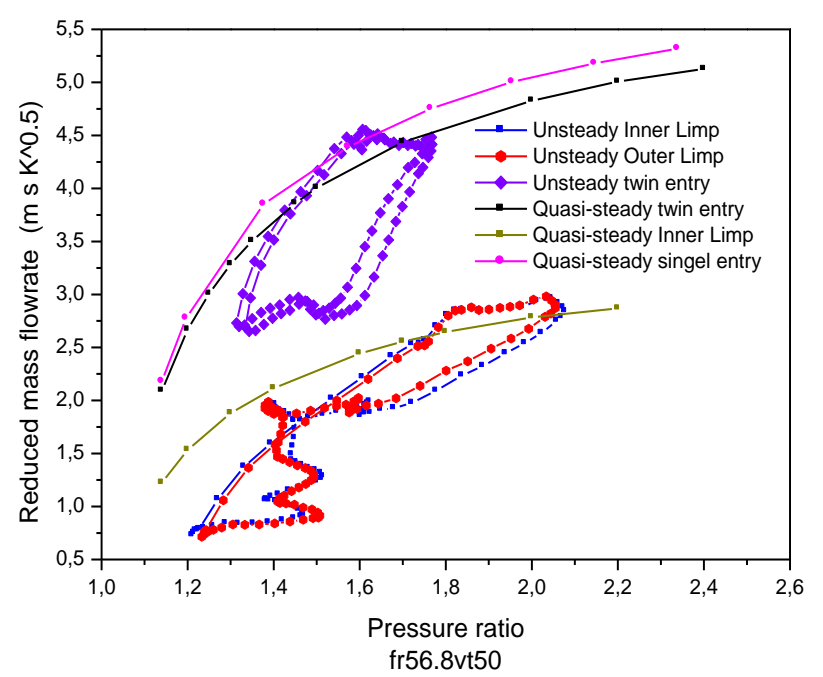



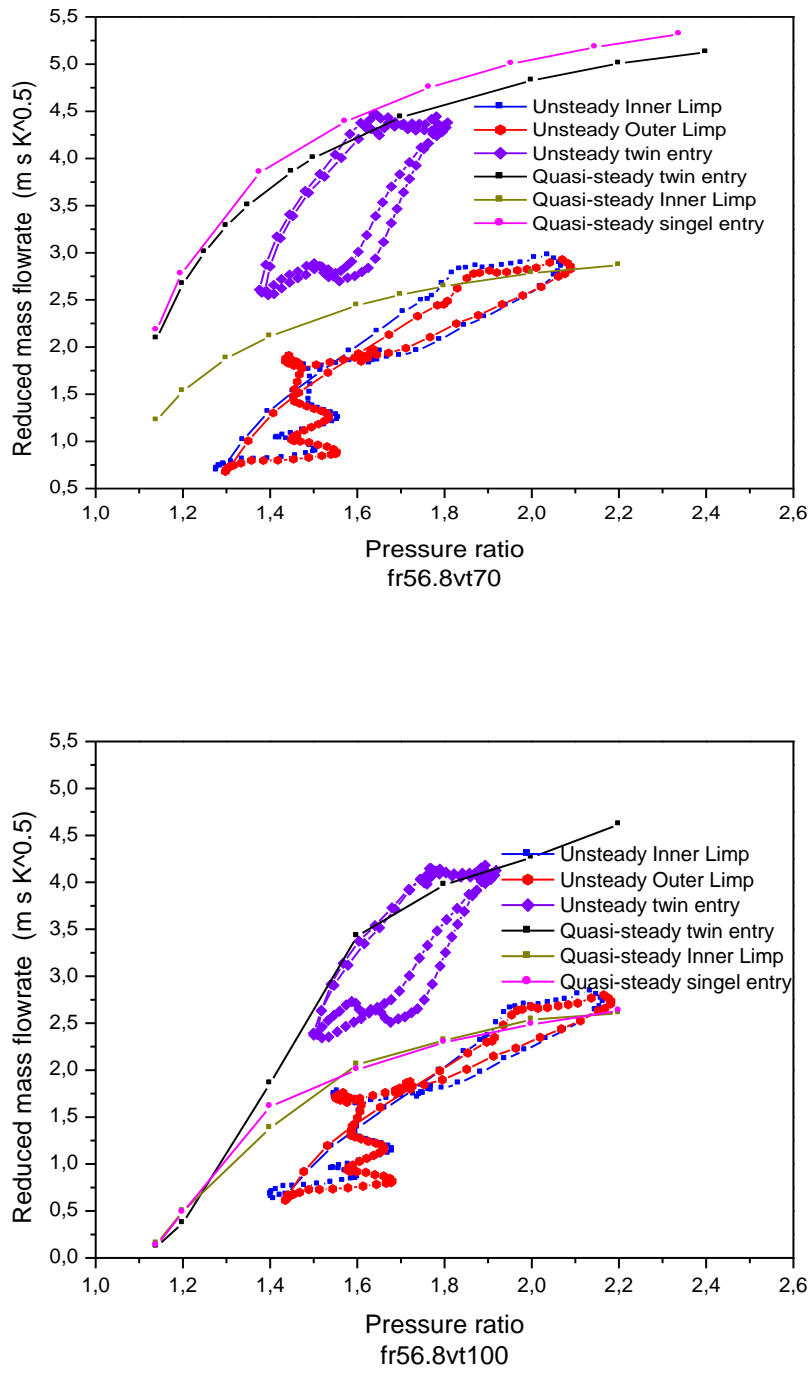

Fig.6. Velocity influence on the performance characteristics of the mixed-flow turbine.

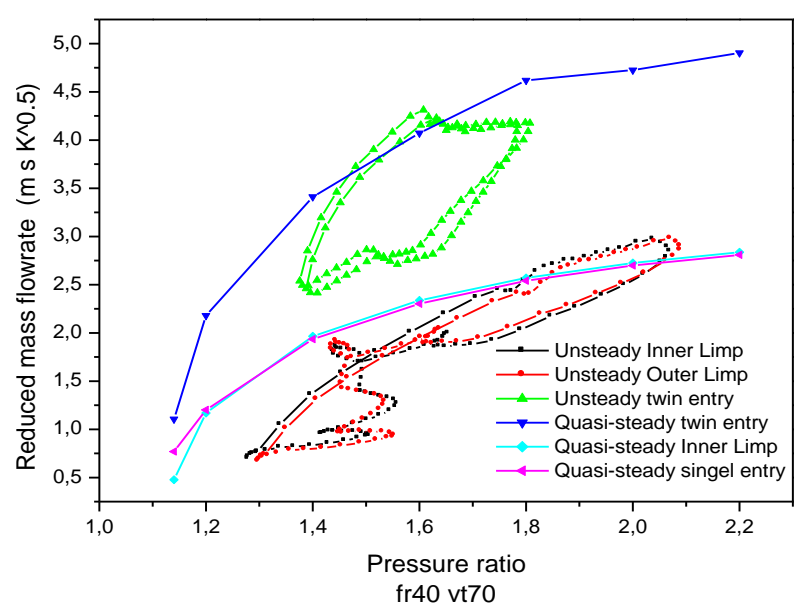

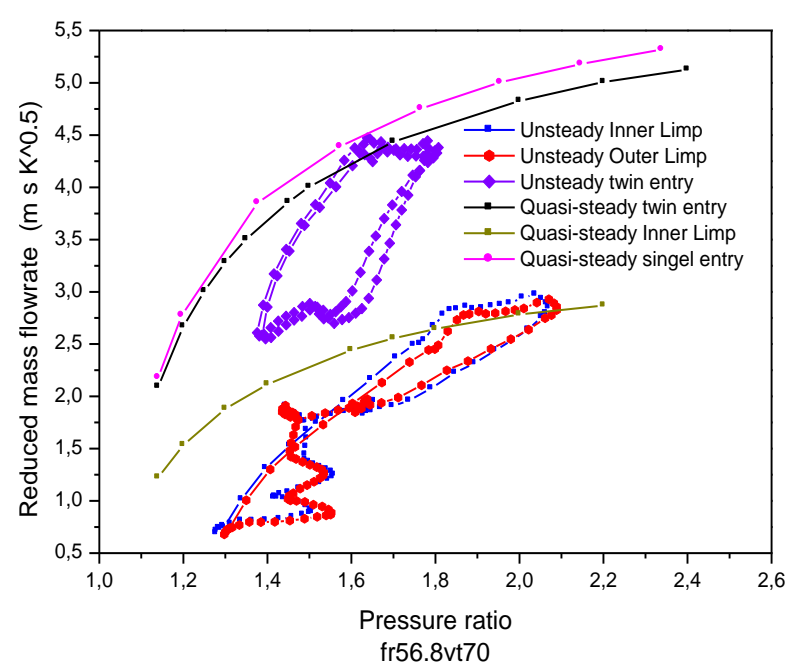

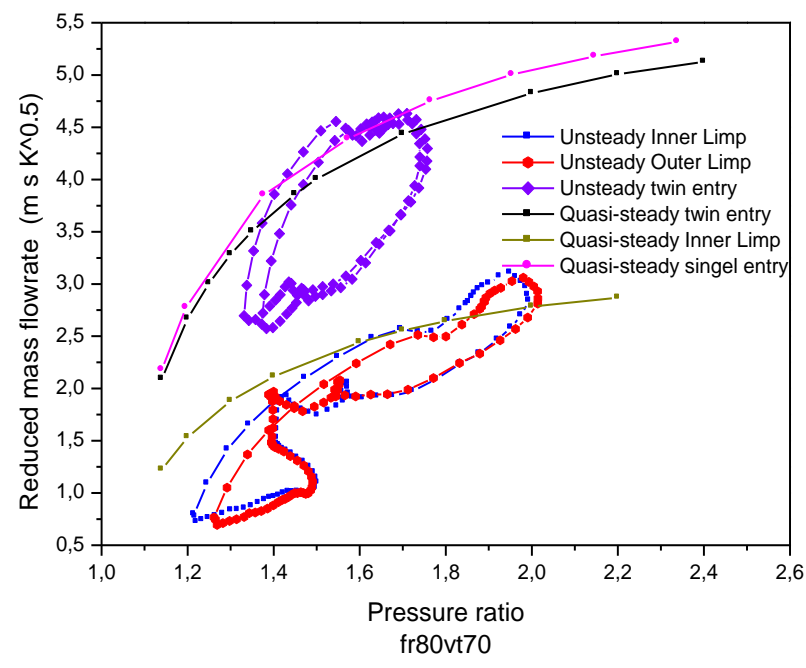

Fig.7. Pulse frequency influence on the performance characteristics of the mixed- flow turbine.

The instantaneous mass flow rate at different frequencies and stations of the twin entry mixed flow turbine stage is shown in Fig. 8. These stations correspond to the turbine inlet (volute twin entry inlet), the rotor inlet, the rotor outlet and the turbine exit (exhaust pipe) respectively. At the turbine inlet, the shape of the instantaneous mass flow rate, for one pulse, is more irregular than the pressure trace. Nevertheless the variation of the mass flow rates follow the main features of the inlet mass flow rate signal for one period pulse at $50 \%$ equivalent speed and $180^{\circ}$ out of phase admission. The minimum inlet mass flow rate, for the three rotation speed, is approximately 
$0.22 \mathrm{~kg} / \mathrm{s}$, while the same remarks apply for the minimum outlet mass flow rates. But, the maximum mass flow rates at twin turbine inlet and outlet are proportional at 50\% equivalent speed. Obviously the turbine does not have enoughto consume the air mass in the working pipe before the next rotation speed; hence, a higher air mass is accumulated in the volute at high frequency, leading to a decrease of the inlet mass flow rate. At the curve for $(50 \%$ and $70 \%$ ), these two curves depart slightly from that of the turbine inlet and are clearly separated at rotation speed $(100 \%)$. The turbine inlet instantaneous mass flow rate is however out of phase from those at the three other stations. There is a degree of time lag associated with the "filling and emptying" of the twin entry volute domain as the turbine acts as a restriction nozzle [16], while the difference between rotor outlet and turbine outlet instantaneous mass flow rates becomes larger when the rotation speed increases. This is also an effect of the "filling and emptying" of the turbine exit pipe.

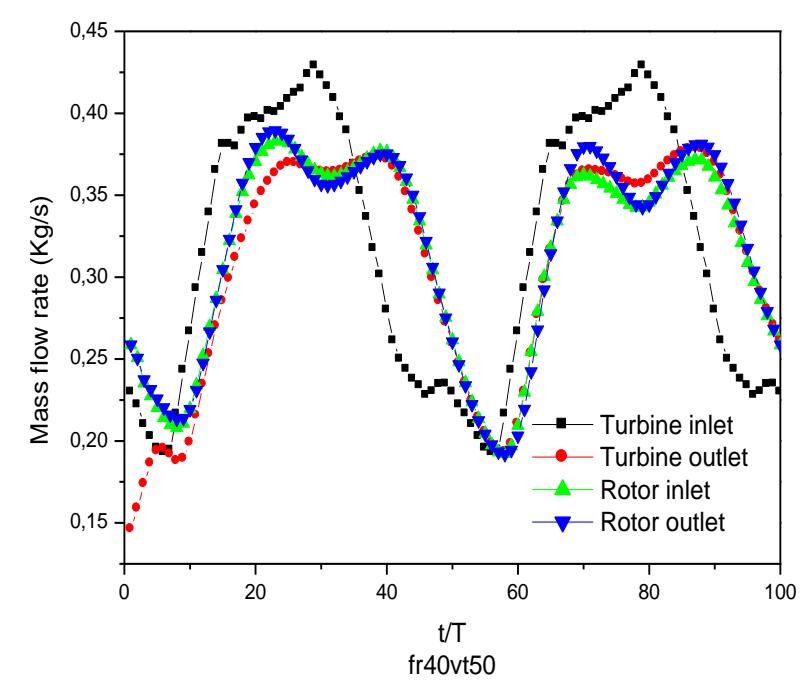

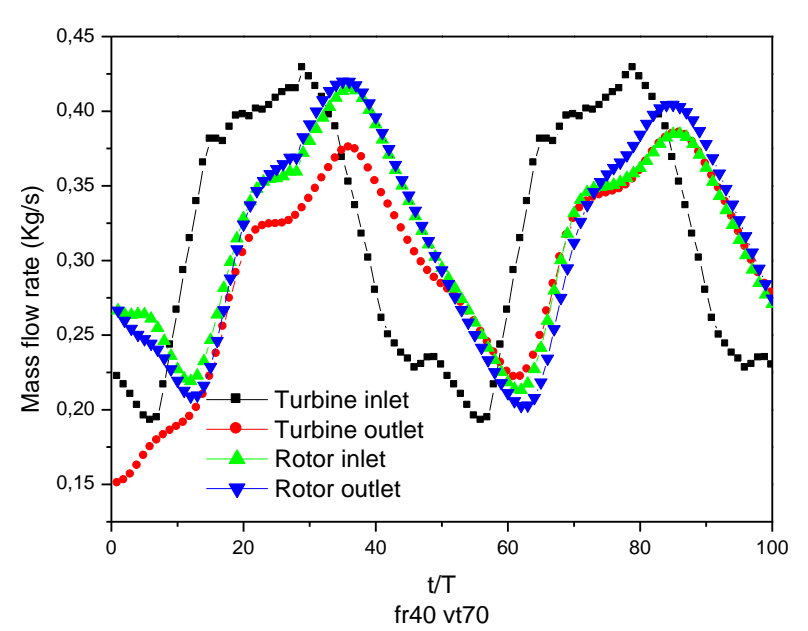

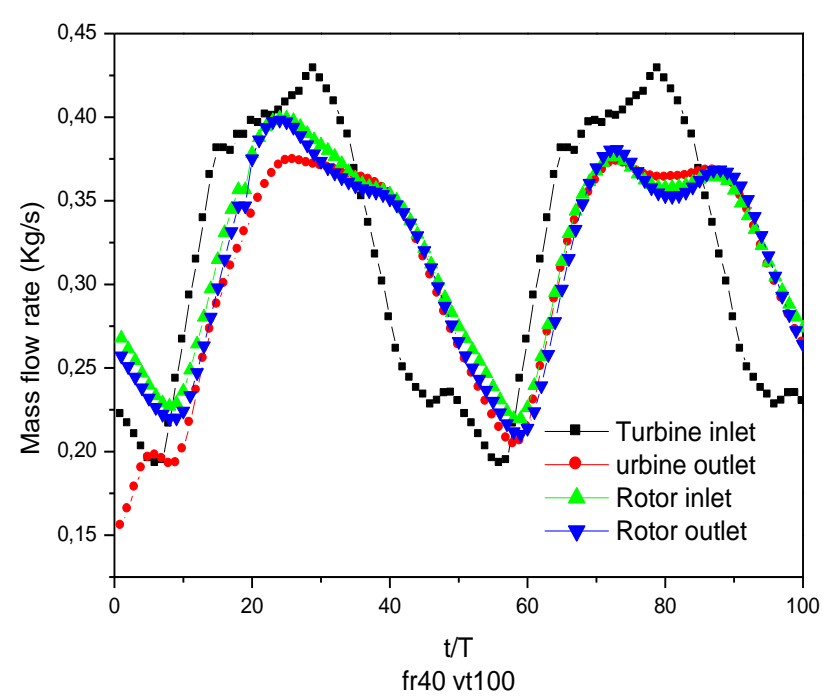

Fig.8. Instantaneous mass flow rate at different turbine stations at $40 \mathrm{~Hz}$ with, $50 \%, 70 \%$ and $100 \%$ equivalent speed.

\section{Conclusion}

We retain from the present study that turbochargers are widely used as a mean of increasing the output power of the machine commonly to road transportation and arise as a case of particular interest suited for less fuel consumption and less pollutant gas emissions. Roughly 30 to 40 percent of the chemical energy released by the combustion is lost in the engine exhaust gas and saved partially in the internal combustion engine cycle with a significant lower outlet temperature to the 
ambient atmosphere. The above focused echosystem considerations are very sensitive to the machine performances as a whole.

Comparative performance estimation is proposed, keeping in mind the eco-system objectives. The steady and transient flow simulations through the components of this twin-entry radial turbine have produced a good insight into the complex flow structures are characterized by a pressure ratio range between 1.1 and 2.4 at $29,500 \mathrm{rpm}, 41,500 \mathrm{rpm}$ and $59,740 \mathrm{rpm}(50 \%, 70 \%$ and $100 \%$ design speed respectively) for both $40 \mathrm{~Hz}, 56,8 \mathrm{~Hz}$ and 80 $\mathrm{Hz}$ pulsating flow inlet conditions and inlet total temperature of $342.2^{\circ} \mathrm{K}$.

The numerical results of the turbine efficiency are compared with the experimental data reasonable agreement is obtained with a maximum discrepancy of $3.75 \%$. The influence of rotation speed and the pulsating flow on distribution of the pressure in the rotor are presented, where the distribution of the Flow in an axisymmetric way at the entry of rotor by transforming the potential energy of gases into kinetic energy conformed to the free the twin entry volute design. And the distribution of the pressure is uniform despite the variation of the pulse frequency.The deviation from the quasistationary approach increases with increasing pulse frequency, as well as the double looping in the overall swallowing capacity representing both entries, which means the twin-entry turbine exhibits more of a filling and emptying characteristic. Finally, the minimum inlet mass flow rate, for the three rotation speed, is approximately $0.22 \mathrm{~kg} / \mathrm{s}$ and the maximum mass flow rates at twin turbine inlet and outlet are proportional at $50 \%$ equivalent speed. Therefore, a higher air mass is accumulated in the volute at high frequency, leading to a reduction in the inlet mass flow rate, while the difference between rotor outlet and turbine outlet instantaneous mass flow rates becomes larger when the rotation speed increases. This is also an effect of the "filling and emptying" of the turbine exit pipe.
References:

[1] United States Environmental Protection Agency,Inventory of US Greenhouse Gas Emissions and Sinks: 1990-2008, Executive Summary. EPA report 430-S-10-001, (Office of Atmospheric Programs 6207J; 2010), $<$ http://www.epa.gov/climatechange/emissions/ downloads10/US-GHG-Inventory

2010_Executive Summary.pdf $>$ (accessed 21.08.11).

[2] TolgaUhlmann, Dominik Lückmann, Richard Aymanns, Development and Matching of Double Entry Turbines for the Next Generation of Highly Boosted, Gasoline Engines Blucher Engineering Proceedings, SIMEA, 2014.

[3] Carla Silva, Marc Ross, Tiago Farias, Analysis and simulation of "low-cost" strategies to reduce fuel consumption and emissions in conventional gasoline light-duty vehicles, Energy Conversion and Management, 215222-2009.

[4] M. M. Bencherif, M. K. Hamidou, M. Hamel, and M. Abidat, Study of unsteady performance of a twin-entry mixed flow turbine, Journal of Applied Mechanics and Technical Physics, 572-300-307, 2016.

[5] M. Hamel, M.M. Bencherif, M. K. Hamidou, Investigation of a twin entry mixed flow turbine volute, benefits with regard to the eco-system, Materials Physics and Mechanics 32 31-42, 2017.

[6] J.Klimstra, Performance of lean-burn naturalgas-fuelled engines-On specific fuel consumption, power capacity and emissions, SAE Paper, 901495, 1990.

[7] Dam J. Feneleya, ApostolosPesiridis, Amin Andwari Mahmoudzadeh, Variable Geometry Turbocharger Technologies for Exhaust Energy Recovery and Boosting, A Review, Renewable and Sustainable Energy Reviews, 71- 959-975, 2017.

[8] UgurKesgin, Effect of turbocharging system on the performance of a natural gas engine, Energy Conversion and Management, 46-1132-2005.

[9] M.Abidat, Design and testing of a highly loaded mixed flow turbine, $\mathrm{PhD}$ thesis, Imperial 
College of Science Technology and Medicine University of London, 1991.

[10] M. Abidat, H. Chen, N.C. Baines, Design of a highly loaded mixed flow turbine, Proceedings of the Institution of Mechanical Engineers, Part A Journal of Power and Energy, 206 95-1071992.

[11] D.B. Vincenzo, M. Silvia, B. Fabio, C. Massimo, ID simulation and experimental analysis of a turbocharger turbine for automotive engines under steady and unsteady flow conditions, Energy Procedia ,45 909 918- 2014.

[12] H. Chen, I. Hakeem, R.F. Martinez Botas, Modeling of a turbocharger turbine under pulsating inlet conditions, Proc IMechE Part A, J. Power and Energy, 210 (1996) 397-408.

[13] C. Arcoumanis, I. Hakeem, R.F. Martinez Botas, L. Khezzar, N.C. Baines, Performance of a mixed flow turbocharger turbine under pulsating flow conditions, ASME, Paper, 210 GT- 95- 1995.

[14] I. Hakeem, C.-C. Su, A. Costall, R.F. Martinez Botas, Effect of volute geometry on the steady and unsteady performance of mixed flow turbines, Proc IMechE, Part A J. Power and Energy, 221 535-550- 2007.

[15] M. Abidat, M. Hachemi, M.K. Hamidou, N.C Baines, Prediction of the steady and non-steady flow performance of a highly mixed flow turbine, Proceeding Institution Mechanical Engineers, Journal of Power and Energy, 212 (1998) 173-83.

[16] M.Hamel, M.K. Hamidou, H.T. Cherif, S.A. Litim, Design and flow analysis of radial and mixed flow turbine volutes. Proceedings of ASME Turbo Expo Power for Land Sea and Air, GT2008-50503-2008.

[17] M. Hamel, M. Abidat, S.A. Litim, Investigation of the mixed flow turbine performance under inlet pulsating flow conditions, J of C. R. Mecanique, 340-165-176- 2012.

[18] M Sakai, A Romagnoli, R F Martinez-Botas, Performance and flow-field assessment of an EGR pulse optimisedasymmetric double-entry turbocharger turbine, Department of Mechanical Engineering, Imperial College London, UK Downloaded From http://www.elearnica.ir.

[19] MahfoudhCerdoun, Adel Ghenaiet,Analyses of steady and unsteady flows in a turbocharger's radial turbine, J Process Mechanical Engineering, 0(0) 1-16- 2015.

[20] S.V. Patankar, D.B. Spalding, A calculation procedure for heat, mass and momentum transfer in three-dimensional parabolic flows, Int. J. of Heat and Mass Transfer, 15 (1972) 1778-1806.

[21] CFX 10 Solver Theory, 2004.

\section{Contribution of individual authors to the creation of a scientific article}

HamidAmrani carried out the simulation and the investigation.

MohamedBencherifhelped in Writing and translating the original draft version of the paper.

MohammedMenaouerBencherifwas responsible for the conceptualizationand supervision.

M. K. Hamidou was responsible for the project administration and supervision.

\section{Creative Commons Attribution License 4.0 (Attribution 4.0 International, CC BY 4.0)}

This article is published under the terms of the Creative Commons Attribution License 4.0

https://creativecommons.org/licenses/by/4.0/deed.en_US 